\title{
Real-Life Problem Solving Skills Required From Office Managers in the Labour Market
}

\begin{abstract}
Adaku Ngozi Achilike
Akanu Ibiam Federal Polytechnic, Unwana, Ebonyi State, Nigeria

Doi:10.5901/mjss.2013.v4n5p169

Abstract

Advancements and growth in technology demands frequent changes in skills and competencies acquisition; prominent among which are problem-solving skills. The study sought employers' ratings on the demands of the labour market for 10-item areas of problem-solving skills generated. The 364 respondents drawn from small scale, medium scale and large scale businesses, later delineated into employers in manufacturing and commercial industries revealed an increase in the level of problem-solving skills relevant for the new millennium for good values in service delivery and creativity in job performance. ANOVA, t-test, mean and SD were utilized for analysis while decision rules were applied meant for business educators in order to enable them impart the right problem-solving skills into secretarial and management students, and for a new curricula to accommodate behavioural objective ingredients that will ensure creativity with zero operational casualties for the graduates while in the labour market.
\end{abstract}

Keywords: manufacturing, commercial, skills, competencies, creativity, maximization, automation

\section{Introduction}

Problem is as old as man while the search for solutions to problems have been confounding and overwhelming for ages now. Howbeit, it is easier to acquire the skill of problem-solving when it borders on ones career or profession provided, of course, that one has imbibed the responsibility of translating into reality both ethics and professionalism in the career (creativity). No nation can rise above the quality of her teachers, says the National Policy on Education (NPE) of Nigeria. In the same vein, no profession can rise above the ability of her members to solve related problems in the labour market. Perhaps, this accounted for the high desire revealed by both managers and business educators for related competencies in office management and administration, reception, office resource administration, information processing, machine operation and other business and secretarial areas (Achilike, 2004; Ojukwu, K. and Ojukwu, F.K., 2005).

The need for maximization of staff efficiency and effectiveness on the job is a strong premise upon which ability to solve problem hinge. Under severe pressure to conceptualize and configure new (even if minute) ideas, skills, abilities that can stem the tide of changes demands problem-solving competencies. With all the ICT projections made now and into the future, only problem solving skills can stand the test of time with rapid advancements coming up; politically, educationally, economically, agriculturally and professionally, etc. It is really obvious that only problem-solving skills can enable a nation grow in a world economy that appears to be changing structurally at the speed of lightening. According to Christensen (2001:105), Today's competitive advantage often becomes tomorrow's albatross. The higher educational sector, of course, becomes the keyplayer in imparting the skills and abilities required in this dispensation. But this cannot be critically and clinically achieved if the opinions of the users of their products are not sought, articulated, analyzed and 
organized in an order that would enable them impact upon knowledge, skills and abilities into graduates that will satisfy the demands of the labour market.

Although it is not contestable that information superhighway has taken the lead as an assessment criteria for measuring a successful graduate in the job sector, it would certainly be contestable that even more imperative is the need for a graduate to sustain his job through problem-solving of cases that intermittently rear their heads in the course of job performance. Ability to solve problem is more relevant in automated environment. Unfortunately, in a pilot test conducted by Achilike (2003), out of 4264 registered companies with the Chamber of Commerce in the six states of south-south geopolitical zone of Nigeria, only 452 were revealed to be automated; given equipment, people and procedure necessary to obtain/upgrade and sustain automation. Now there is great improvement in automation but the users are still as obsolete as they were ten years ago as a result of shear inertia. Thus the need to ascertain the need for problem-solving skills in the office education programme as perceived by large scale, medium scale and small scale employers in manufacturing and commercial industries. Their rating of the skills will be divided into the 10-item ability areas of:

1. Ability to understand complex matters and simplify them.

2. Ability to display good initiative in the absence of supervision.

3. Ability to exhibit appropriate change for different purposes

4. Ability to accept delegated authority.

5. Ability to display compatibility skills with the environment.

6. Ability to handle superiors, peers and subordinates.

7. Ability to design protocol.

8. Ability to handle visitors, customers and clients.

9. Ability to handle innovations.

10. Ability to handle to impart and manage knowledge.

\section{Problem and Purpose of the Study}

The quest for problem-solving antics has led to globalization and developments thereto. Hitherto, things had been done in just one correct way or one way in which the office/boss wanted them done. Now, it has been made obvious, through problem solving that various ways could be applied to the achievement of a purpose while the search for the best way has created the possibility of many more acceptable best ways, depending on one's initiative and the level of acceptability of the environment concerned. The bane of Nigeria's apprenticeship system has not helped matters- we have skill acquisition centers proliferated all over the country with illiterates, taught in mother-tongue, limited follow-up and inadequate funding as well as the hitand-run syndrome of trainees, thus impacting negatively on problem-solving and creativity. Functionality of education in this case could predicate upon the impartation of knowledge leading to the acquisition of the desired skills for solving problems in the office, management and education professions.

The awareness of consumers and other members of the society to their sovereignty are such that satisfaction must be achieved by applying the skills aimed at divergent and variety in order to eradicate routine which made office and other jobs monotonous and boring. After appreciation and awareness, knowledge and skills comes problem-solving aimed at application and synchronization and synthesis for proficiency in the mastery of skills and competencies (Wahab, 2005; and Shyllon, 1992). A good sense of commitment ensures that the secretary and other office workers know when to do what and how, utilizing the problem-solving skill and making him adaptable and resourceful and also useful in optimum service delivery.

The breathtaking technological advances of the last decades have served a good reminder that problem-solving skills should not just be imparted in line with moral values advocated for our new National Policy but at the same time suggests an increase in the level of problem-solving skills relevant for the new millennium. It demands an unshakable commitment in imbibing cultural values for the eradication of all forms 
of vices to become a necessity aimed at a National image branding that would create good value orientation for service delivery in various sectors of the economy.

Without problem solving, office staff would not be able to deliver good services to their bosses, superiors, colleagues, and clients in the various sectors of the labour market. Information necessary for decision-making is a sine qua non with the secretary and other office workers, as a key-player in the circle, considering that many forms of information would naturally yield wrong result - garbage-in-garbage-out (GIGO), if not properly utilized. Utilitarian value of a good service delivered could be rubbished where time value is not applied while certification without the enabling skill, knowledge and abilities creates no utilitarian value in its application. Problem solving skills not hinged on knowledge, ethics and morals, understanding of human nature (to take care of personnel) would only make a mockery of what is on ground. The effectiveness of the skill, however, can only be determined by employers/directors personnel i.e. through different appraisal techniques.

In the light of the above, the problem was what problem-solving skills do employers rate as necessary for satisfying their higher office/administrative demands in the labour market while the major purpose was to ascertain the importance rating of office/administrative problem-solving competencies expected by employers of such level of personnel in manufacturing and commercial industries as well as to determine the extent to which size of business could be of influence in their rating. Statistical tools at 0.05 significance level were utilized for both ANOVA and t-test analyses.

\section{Research Question}

1. What problem-solving skills are required of secretarial/administrative staff in the labour market?

\section{Hypotheses}

1. The importance ratings of employers in manufacturing and commercial industries do not differ statistically with regard to problem-solving skills.

2. There is no statistically significant difference in employers' rating of problem-solving skills, as a result of the size of employers' firms.

\section{Methodology}

Attracting the desired survey design, the study had a population sample of 364 employers of labour/directors of personnel derived from automated offices in the six states of the south-south geopolitical zone of Nigeria, after six of them have been used for pilot test that yielded 0.82 reliability coefficient. Eighteen of the employers are in small-scale business, 126 are in medium scale business and 220 are in large-scale business. The questionnaire used as instrument for data collection was assigned numerical values of 5-highly required, 4-required, 3-undecided, 2-not required and 1 highly not required; for purposes of eliciting responses from respondents on the 10 -item skills enlisted for rating.

The null hypothesis with three variables attracted ANOVA statistical tool while the one with two variables attracted t-test tool, as appropriate for the analysis of data. The research question was analyzed using mean statistics and SD (standard deviation) with a mean of 3.5 and above designated 'not rejected' as required while those below were rejected. The null hypothesis with calculated t-ratio or f-ratio less than the critical value of 't' or 'f' was not rejected while the one with calculated t-ratio or f-ratio greater/equal to the critical value was rejected.

\section{Findings}


Table 1: Respondents' Mean Rating of Office/Administrative Problem-solving Skills of Graduates

\begin{tabular}{lcccccc}
\hline & \multicolumn{2}{c}{$\mathrm{S} S, \mathrm{~N}=18$} & \multicolumn{2}{c}{$\mathrm{M} S, \mathrm{~N}=126$} & \multicolumn{2}{c}{$\mathrm{LS}, \mathrm{N}=220$} \\
Competencies & $\mathrm{X}$ & $\mathrm{SD}$ & $\mathrm{X}$ & $\mathrm{SD}$ & $\mathrm{X}$ & $\mathrm{SD}$ \\
\hline 1. & 3.09 & 1.58 & 4.62 & 0.58 & 4.58 & 0.58 \\
2. & 3.64 & 1.63 & 4.69 & 0.56 & 4.58 & 0.77 \\
3. & 4.18 & 1.60 & 4.55 & 0.63 & 4.32 & 0.79 \\
4. & 3.82 & 1.47 & 4.50 & 0.59 & 4.33 & 0.99 \\
5. & 3.64 & 1.36 & 4.36 & 0.57 & 3.95 & 1.21 \\
6. & 3.27 & 1.49 & 4.27 & 0.94 & 3.98 & 1.13 \\
7. & 3.46 & 1.64 & 4.51 & 0.86 & 4.49 & 0.96 \\
8. & 3.82 & 1.47 & 4.31 & 0.47 & 4.14 & 1.17 \\
9. & 3.64 & 1.36 & 4.37 & 0.66 & 4.49 & 0.62 \\
10. & 3.64 & 1.50 & 4.45 & 0.50 & 4.28 & 0.99 \\
\hline Average & 3.62 & 1.33 & 4.46 & 0.31 & 4.32 & 0.63 \\
\hline
\end{tabular}

\section{1-10 represents the 10-item office/administrative problem-solving skill areas enunciated in the text. SS means small scale; MS means medium scale, LS means large scale.}

A critical look at table 1 above reveals the picture that employers in SS businesses rated as 'not required' the ability to understand and simplify complex matters, ability to design protocols and ability to handle visitors, customers and clients. All the skills were rated as 'required' for both MS and LS employers, although at different levels.

Table 2: T-test Result of Employers' Mean Rating on Office/Administrative Problem-solving Skills of Graduates in Manufacturing and Commercial Industries.

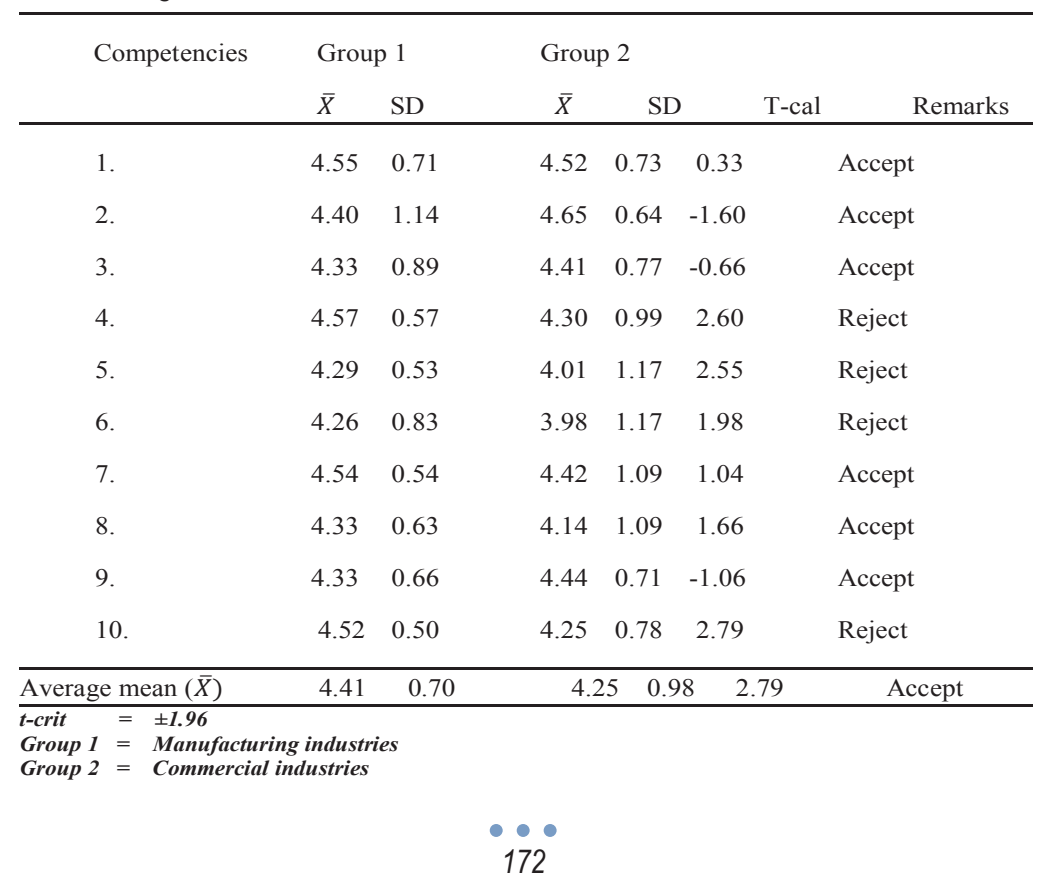


The t-test table above shows that there is no significant difference between the ratings of employers in manufacturing and those in commercial industries, for abilities to; understand complex matters and simplify them, display good initiative in absence of supervision, exhibit appropriate change for different purposes, handle visitors/customers and clients, subordinates/peers and superiors. Their calculated values of 't' were lower than the t-crit of \pm 1.96 and thus subjected the null hypothesis to acceptance. Conversely, abilities to; accept delegated authority, display compatibility skill with environment, design protocol and impart and manage knowledge attracted a significant difference between rating from the two groups of employers. The null hypothesis was rejected because the calculated values were higher than the t-crit.

Table 3: ANOVA Test on Respondents' Rating Regarding Office/Administrative Problem-solving Skills of Graduates According to Sizes of Business

\begin{tabular}{llrll}
\hline Source of Variance & Sum of Squares & df & Mean Squares & F-cal \\
\hline Main Effects & & & & \\
SIZE & 7.09 & 2 & 3.55 & 10.19 \\
Explained & 7.09 & 2 & 3.55 & \\
Residual & 83.12 & 239 & 0.35 & \\
\hline TOTAL & 90.21 & & 241 & 0.37 \\
\hline F-crit $=3.00$ & & & & \\
Remark $=$ Reject & & &
\end{tabular}

Table 3 above indicates that employers statistically differ in their ratings according to the size of their firms, in their opinion over the need for graduates of Secretarial, Office and Administrative positions to acquire the skills of problem solving. As a result, the null hypothesis of no significant difference was rejected accordingly.

\section{Discussion and Implications of Findings}

The fact that only employers in small scale businesses registered ratings revealing low requirement for problem-solving in understanding complex matters and simplifying them, designing protocols and handling visitors/customers/clients presupposes that the bigger a business, the more complex its problems. Skills requirement would therefore differ in degree, according to Little (1983). The finding is in consonance with Njoku and Nwosu (2002) that very few proprietors of small-scale businesses bother about proper management, as a result of which many fail and others experience poor growth. Business educators, whose graduates are expected to create more jobs in the labour market, are therefore not to regard this low rating since the graduates would require their businesses to grow through on-the-job training for their own employees who may later find themselves in medium and large scale businesses. This will further encourage government's policies on NEEDs (National Economic Empowerment Development Strategy) and MDG (Millennium Development Goals) and this may be their own counterpart contribution to the national economy.

It was also revealed that both manufacturing and commercial industries highly require office/administrative staff to have abilities to 'understand and simplify complex matters'; 'exhibit appropriate change for different purposes'; 'display good initiative in the absence of supervision'; 'handle visitors/customers/clients, superiors/subordinates/peers and handling innovations'. Every business has its aim as profit maximization and continuous growth and it is obvious that these could be guaranteed through problem-solving skills as well as its application in various degrees, depending on the need. In line with 
government economic reforms, the new economic communities begging for consistent and clinical jobs creation to take care of the teeming graduate influx into the job market will be a thing of the past if there is a conscious effort in ensuring the acquisition of problem-solving skills by the staffs which constitute Business, Management and Education graduates.

The ability to accept delegated authority would manifest in the performance of duty to best of ability depending on one's value for superior; for his job, for the family on which he owes responsibility of care and on society. This will ensure patriotism thereby erasing corruption and sharp practices in order to enrich oneself and thereby destroying the nations' work system. Ability to design protocol would on the other hand create job satisfaction, promotion and growth of business. However, the significant difference recorded in the requirement between manufacturing and commercial industries recognizes the environments and level of needs in the two sectors. This does not negate Azuka (2000) exposition of the need for office/administration students to acquire various skills of problem solving in their work places in order to strike a balance in the warring between economic realities and technological advances which has necessitated focusing on knowledge and information of the new millennium.

The high requirement for the handling of the different people with whom the officers will relate in the course of duty were supported by the highlight of Obi (2001) and Onyekwere (2001) on the importance of good vocabulary, diction and word selection inter-personal relationships. Handling colleagues should include making everyone feel human by exhibiting no snobbery, no sacred cows/blacklegs, etc. The intricacies of various types of human beings in the large-scale businesses would necessitate more rigorous, stiffer and technical problem-solving skills for efficiency. Ability to handle visitors entails treating them with decorum. Dressing and grooming by the officer comes in here, as some appearances of the employee could be embarrassing to visitors. Sexual harassment of visitors would be minimized and where foreigners constitute visitors, then the image branding should be brought to bear on handling them. Ability to impart and manage knowledge necessitates that employees should be capable and willing to teach/train others on what they know while at the same time protecting confidentiality on the job. Tact is highly required here. The indispensability of problem-solving skills to occupational outcomes appears to be emphasized by the acknowledgement of many respondents to their high requirements from the graduates in order to satisfy market demands for creativity. Ekpenyong (1992) had observed that the way individuals set about solving problems particularly when threatened or challenged, is an indication that adequate degree of motivational situations would generate creative outcomes from individuals at varying degrees.

\section{Conclusion}

Combination of advancements in technology and government economic reforms which brought into limelight; NEEDS, MDG, etc has generated the need for problem-solving skills to be acquired by graduates who will occupy the positions of office and administrative staff. The rating of the high requirement for these skills is an indication that they require them not only to obtain jobs but also to sustain their stay in their jobs as well as to make the nation grow. Creativity was seen as a necessary ingredient in the preparation of the secretary and administrative staff for problem solving skills acquisition while capacity building for the educators was derived from findings

\section{Recommendations}

1. Capacity building for business educators should be put in place periodically in order to equip them for imparting current problem-solving skills to their students (graduates).

2. The new curricula being considered now should have acquisition of problem-solving skills majorly weaved into the behavioral objectives. 
3. Increased computer packages should be used as tools in secretarial teaching, as an aid to creativity.

4. Reflective thinking, unusualness and cleverness of response should be awarded benchmark grades to encourage problem solving skills.

5. Zero operational casualties on the job should be encouraged through series of group activities based on oral exchanges, tolerance and acceptance of useful minority opinions, as well as elements of newness and cleverness in job tasks.

6. Simulations on real-life situations depicting problem-solving should be enhanced and encouraged in teaching and learning.

\section{References}

Achilike, A.N. (2004). Communication competencies expected of Higher National Diploma (HND) Secretarial Administration graduates by employers of labour. Anpublished PhD dissertation of Nnamdi Azikiwe University, Awka.

Azuka, E.B. (2000). Challenges of a professional secretary: Need for curriculum revisionln Nigerian Polytechnics. Business Education Journal, 3(3), 38-48.

Babalola, L.S. (2001). A guide towards effective curriculum development for the training Of secretaries in the era of advanced technology. Business Education Journal, 3(4)10-16.

Ekpenyong, L.E. (1992). Creativity: A forgotten concept in Education (Implications forVocational curricula). Nigerian Journal of Technical Education, 9(1\&2), 49-63.

Elendu, E.O. (2001). The Perfect Secretary. Aba, Nigeria: MacElendu \& Co.

Little, P. (1983). Communication in Business. New York: Longman Group Ltd.

Njoku, C.U. and Nwosu, A.N. (2002). Role of Business Education in sustaining small scale Businesses for national development. Business Education Journal, 3(5), 95-106.

Obi, C.A. (2001). Communication skills needed by university graduate employees for Successful job performance in business organizations. Journal of Business and Office Education, 1(2), 51-60.

Ojukwu, F.K. (2005). Managers and Business Educators' perception of the competencies Required in modern computerized offices. Business Education Journal, 4(1), 137-145.

Onyekwere, O. (2001). The role of effective communication in achieving organizational Excellence. Journal of Secretarial Administration, 1(1), 76-81.

Schofield, H. (1979). The philosophy of Education: An introduction. London: George Allen And Unwin Ltd.

Shyllon, A.K. (1992). Word processing: New trend in the secretarial profession. Business Education Forum, 1(1), 4-6.

Wahab, A.A.A. (2005). Making Senior Secondary School graduates employable in an ICT Environment. Business Education Journal, 5(1), 49-56.

Woods, R.G. and Barrow, R.S. (1975). An introduction to philosophy of education. USA: Menthuen \& Co. 